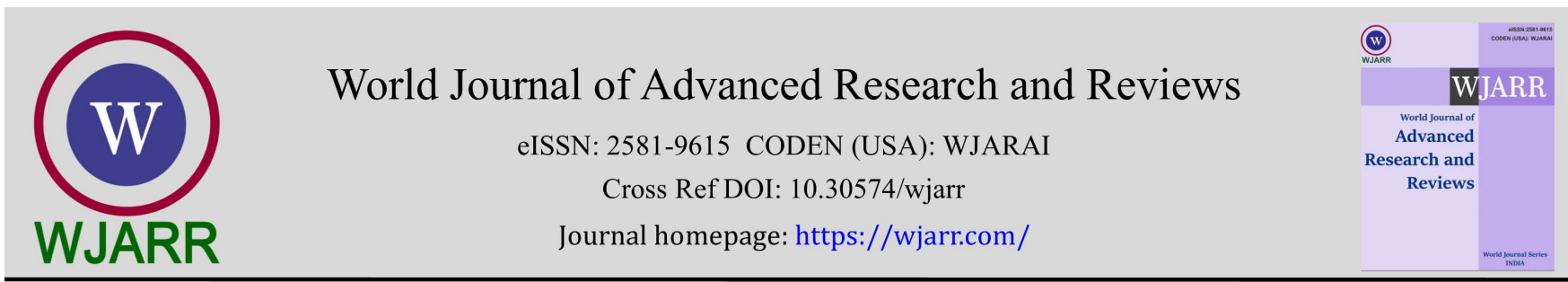

(RESEARCH ARTICLE)

Check for updates

\title{
Examining factors that affect staff performance in Lesotho Correctional Service
}

\author{
Bernard Nkala ${ }^{1, *}$ and Phaello Olivia Malataliana ${ }^{2}$ \\ ${ }^{1}$ Institute of South South Cooperation \& Development Peking University, China, \\ 2 Department of Lesotho Correctional Service (Operations), Lesotho.
}

World Journal of Advanced Research and Reviews, 2021, 09(03), 148-158

Publication history: Received on 04 March 2021; revised on 06 March 2021; accepted on 09 March 2021

Article DOI: https://doi.org/10.30574/wjarr.2021.9.3.0087

\begin{abstract}
Staff performance remains critical in every organization's and indeed country's' performance hence factors critical for ensuring high performance must always be interrogated. Using conclusions from survey data from 700 Lesotho Correctional Service employees, the study sought to examine the factors that affect performance, assessing the extent to which variables; leadership style, employee participation, working environment, organizational culture and motivation impact on employee performance. The research sample consisted of Correctional Service employees picked from six departments/units out of 13 using a probability one's stage cluster sampling design. The subjects were randomly selected from a target population of 1000 employees to understand the factors that affect employee performance. The sample included the civilian staff, senior management, middle management and subordinate level staff mainly to balance views. The use of questionnaires, semi structured interviews and researchers' observations was utilized to collect research data for analysis. The study reviewed departmental policies and published literature on Correctional and Prison services staff performance, behavior and satisfaction as a theoretical base to endorse study independent variables.
\end{abstract}

Data revealed that work environment was perceived to have the greatest influence on Lesotho Correctional Service employee performance (mean=4.88). Other factors include organizational culture (mean=4.77), employee participation (mean=4.22), leadership style (mean=3.51), employee empowerment (mean=3.67), employee motivation (mean=3.65) and employee training (mean $=3.89$ ) indicated as affecting employee performance. The study revealed that the style of management, low salaries and allowances, flawed legislation, lack of appropriate human resource policies, and limited development opportunities affect staff performance. Regression estimation using n450 responses between study dichotomous dependent variable (employee performance) and independent variables; leadership style, employee participation, working environment, organizational culture and motivation proved all the independent variables significant in explaining employee performance. The five independent variables studied explain $67.4 \%$ of the staff performance in the Lesotho Correctional Services as represented by the R2. The study recommended institutionalization of the performance reward system, incentivizing ethical conduct to enhance professional conduct amongst the officers, enhancement of team work, pioneering leadership training and revising and strengthening the current performance management system as amongst strategies that can enhance Lesotho Correctional Service employee performance.

Keywords: Correctional Service; Staff performance; Motivation

\section{Introduction}

Employee performance has always been at the core of human resource management of any institution. Bohatala [1] is of the opinion that employee performance is the foundation of any organization's performance and the factors critical

\footnotetext{
${ }^{*}$ Corresponding author: Bernard Nkala

Institute of South South Cooperation \& Development, National school of Development, China.
} 
for ensuring high performance must always be interrogated by the organizations. It is an undeniable fact that organizations can only achieve their set goals and objectives if employees perform maximally. Mboi states that, in recent times there has been a clarion call around the globe for improvement of public sector performance due to the fact that the sector receives significant amounts of funding from the government as well as the public [2]. Mboi continues to state that restructuring and reforms in the public sector have been household names in recent times which have been aimed at improving performance and efficiency but from the experience of many public servants, the result has been redundancies, intensification of work and an increase in activities that do not make any material contribution to the delivery of services [2]. The Lesotho government saw numerous public sector reforms since 1969 targeting on improving performance and productivity [3]. It is worth noting that in the advent of democracy, there has been notable decline in performance of public service in Lesotho where there has been an outcry of politicization of the service [4]. The study looked into factors affecting performance of employees in Lesotho Correctional Service within the Ministry of Justice and Correctional service. The department is paramilitary in nature, where the officers undergo military training prior to their deployments.

However, in recent times Lesotho Correctional Service has been plagued by decline of staff performance, frequent change of departmental top administrators, that has been claimed brought a lot of instability and uncertainty to both staff and inmates [5]. The decline in staff performance is seen through outcry by public on the ill-treatment of the inmates [4], notable decline of staff discipline seen through staff participation in political activities and staff soliciting for relief from Ombudsman and Parliament regarding staff promotions and recruitment viewed as politically motivated. The Lesotho Correctional service annual Reports 2015/2016 and 2016/2017 and 2017/2018 indicate the numbers on discipline cases increased from 24 to 35 to 42 respectively. The study sought to examine determinants of staff performance in the Lesotho Correctional Service. The research hypothesized there is a significant positive relationship between motivation and performance of employees and the leadership has a significant positive influence on performance of employees.

Formerly a British Protectorate, Lesotho gained her independence in 1966 and the influence of British in the administration of civil service is noticeable. For example, Lesotho Correctional Service had been using the 1957 Proclamation in the administration of the department until 2016 when the LCS Act 2016 was passed. The writings of [6] state lack of clear policies and procedures led to recruitment being open to abuse and less transparent in the public sector. Furthermore, Monyane asserts that the civil service has always had challenges of low morale amongst employees, lack of eagerness to perform duties which ultimately resulted in poor provision of services attributed to politicization of public institutions, low salaries and allowances, and poor working conditions [7]. Lesotho has seen industrial actions in military $(1994,1998)$, correctional service $(1994,2016,2017)$ teachers $(1994,2018)$, police $(1994$, 2016) where employees were protesting against low salaries and allowances.

\subsection{Theoretical implications}

The study is modeled around the human relations theory of management aimed at increasing productivity and reducing labor costs [8]. Mayo's discovery was that, work was more a social atmosphere where the interaction between leaders, employees and observers affected productivity. He further found out that the physical conditions were not as important as recognition and attention afforded to employees [9]. There are other sets of theories that looked into employee motivation and how it affects performance. The expectancy theory proposes that the level of performance by an individual is dependent on the expectation that the effort an employee exert will be accompanied by an appealing outcome [10]. The theory assumes that employees deliberately decide whether to perform or not and on how much effort they can put in the execution of the job dependent on valence, expectancy and instrumentality. Heathfield suggests that the theory gives pointers for managers in that, it is their role to ensure employees achieve expected performance levels and that deserving employees are rewarded for their exceptional performance, reward system must be fair and just, employees' motivation be assessed continually [11]. Numerous studies have been done on the factors that affect the performance of workers in various organizations, be it private or public institutions. The data from such studies have been used to inform human resource policies in different jurisdictions. However, there seems to be scanty literature on factors that could enhance performance in correctional institutions more specifically in developing countries which are mostly paramilitary and always grapple with limited budgets yet their role in national security cannot be overlooked. There seems to be limited empirical evidence on how leadership and organizational justice affect performance of employees in correctional institutions. In this study the independent variables are leadership, motivation and organizational justice while the dependent variable is employee performance.

It remains imperative for organizations to interrogate employee performance because it remains critical in the overall performance of an organization [12]. Managers therefore need to make deliberate decision of ensuring that employees' performance is geared towards achievement of institutions mission and plans. There appears no one size fits all 
approach when dealing with human beings because everyone is different [13]. Some employees have the highest capability regardless of the incentive, while others may have an occasional jump-start. Despite employees differing in their capabilities, if all employees are managed well, the results can be motivated employees hence enhanced output [13]. In reviewing factors affecting employee performance, [14] view a motivated workforce is critical as profitability and productivity of any organization depends on involvement and participation of all employees. The author [15] is of the conviction that motivation plays a critical role in employee performance as it allows employees to channel their efforts towards attainment of organizational goals. According to [16], motivated employees lead to enhanced comprehension of objectives and decision making between management and employees hence better commitment to implementation. Furthermore, the work environment plays a role in employee performance. Employees get motivated knowing that management considers them as partners in contributing to organizational success instead of being seen as mere subordinates and therefore will avoid engaging into counterproductive behaviors hence better performance through attainment of organizational goals and objectives [17].

Most of the literature studied looked at employee performance in general but [18] are of the view that job satisfaction of correctional staff needs to be fully understood because high levels of job satisfaction has been linked to positive behaviors, such as support for rehabilitation and overall performance, and minimal job satisfaction has been linked to negative behaviors, such as absenteeism and turnover. It is very important for correctional administrators to focus on increasing positive behaviors while reducing negative ones especially in an era of increasing demands for improved performance and strained budgets. Nacci as cited [18] argues that when officers recorded greater job satisfaction, inmates were likely to say that their environment was freer from danger of sexual assault. On the other hand, [19] found among Naval correctional staff that those staff who reported higher levels of job satisfaction indicated a more positive view of incarcerated individuals and had a stronger attitude towards rehabilitation. Understanding the possible causes and effects of correctional staff job satisfaction is then very important for correctional administrators. Negative employee work behaviors are detrimental and even devastating for correctional organizations because correctional facilities are dependent on staff to successfully complete the myriad tasks [20].

Hwang and Thao mention the factors; leadership, coaching, participation, empowerment, organizational culture, motivation, working environment and training that affect performance [14]. On the other hand, [21] assert that employees do not perform in a vacuum, rather a variety of factors; personal, company-based and external affect their performance hence knowing these factors can lead to improved recruitment, retention of staff and organizational results. On the other hand, [22] state that there are key factors i.e. job self-sufficiency, managerial support, distributive fairness and routine impartiality in the employee's workplace environment that impact greatly on their level of enthusiasm and performance. In trying to understand the factors that could affect performance of employees, Frederick Herzberg proposed a two-factor theory or the motivator-hygiene theory suggesting satisfaction and or dissatisfaction depends on different job factors [23]. There is consensus among researchers that employee motivation and satisfaction can be affected by both internal and external factors. However, [24] has summarized the factors influencing employee motivation; the organization, nature of work, level of satisfaction and supervision, worker's perception of reward system; in a very concise way hence the considered as study variables.

Effective leadership in any organization is key in the functioning and efficiency of such an organization [14]. Therefore, effective leadership is the foundation or heart of any organization thus a central feature of organizational performance. If an employer does not provide feedback on good performance, communication gap will be created leading to decline in performance [25]. Leaders have to keep up performance, sustain performance while at the same time have to keep checking on performance indicators, promote innovation and risk taking and skills for future development [26].

Every leader has certain traits and behaviors that make people to follow or not thus having certain leadership competencies and skills often lead to ability to attain organizational goals and objectives through use of differing styles depending on the situation [27]. At the individual level, leaders who are able to influence, encourage and direct employees will get devoted employees who are willing to perform their jobs exceptionally well [27]. Autocratic leaders proved to be the inexperienced types who often assume leadership roles upon being given a task to lead or manage [28]. Amongst leadership styles, autocratic leaders retain for themselves the decision- making rights and often drive an organizational spiral downfall as they force their subjective perception strategies upon members, disliking employees' commitment, innovation, loyalty and motivation [28]. However, a leader with transformational capabilities is visionary and strives for transformational leadership behaviors as: attributed charisma, idealized influence, inspirational motivation, intellectual stimulation, and individualized consideration [29]. There is substantial ground that transformational leadership provides opportunity and confidence to subordinates to achieve organizational goals, maximum performance and act in solving problems in new ways. Bohatala [1] argue that with democratic leaders, employees are given an opportunity to participate, ideas are exchanged freely, and discussion is encouraged. Leaders with a democratic approach use indirect communication patterns to facilitate for members to reach consensus, 
enhancing groups contributions and effectiveness [27]. Employees tend to perform well in organizations where they are given freedom to perform whilst at the same time being acknowledged. On the contrary, in organizations where employees are not allowed to contribute and being dictated on, motivation is lessened and this has been attributed with declined performance [21].

A study by [30] conducted in Pakistani banks trying to examine the impact of managers' leadership styles on subordinates' performance revealed that there is a positive significant relationship between transformational leadership and employee performance. However, the study indicated the authoritarian style showed negative relationship between the performance of subordinates and managers where employee performance was gauged in terms of effectiveness and satisfaction. In another study that was conducted [31] in Nigerian public sector using a case study of department of petroleum resources, using the variables of transformational, transactional and laissez faire leadership styles on employee performance constructs of organizational commitment, organizational citizenship behavior and job satisfaction, established that the leadership styles had a positive relationship on performance of employees. The study discovered that transformational leadership style is the best approach to be used for any organization that wishes to meet its targeted aims and goals through improved performance of its employees [31]. The researchers concluded by recommending that managers should use more of transformational leadership to bring about higher levels of organizational commitment, and job satisfaction.

In fact, [32] assert performance management system was introduced by China in an effort of enhancing performance of employees. Burns is of the opinion that performance measurement has been widely used in China's public sector to enhance performance and ensure accountability [33]. Just like other economies that went through reforms, the civil service embarked on China's civil service reforms in 1993 on a trial basis [32,33]. One strategy that has been critical in enhanced performance of employees has been use of incentives or performance-based reward system. The China's Civil Servant Law has a clause that states that promotions of officials should be based on the principles of "both moral integrity and ability, and appointment of those on merits, paying special attention to work accomplishments" [32]. Amongst the lessons taken from China's implementation of the incentive system is the establishment of clear policy framework of how incentives are to be administered in the process political interference and reducing incidences of corruption on promotions [32,33]. Another strategy that has been instrumental in the performance of civil servants of china is the Objective Responsibility System [33] that involves setting objectives for other smaller government units and ensuring that individual leaders are responsible for the achievement of the set goals. Bivins is of the view that human beings seek accountability and want to know who is responsible for certain actions and who is accountable for the consequences of those actions [34]. Therefore, there is substantive evidence that leadership styles play a role on employee performance. The study believes variables leadership, motivation types, working environment and policies on employee development and participation are likely to positively influence employee performance. However, the above assumptions need to be equally tested in the Lesotho Correctional Service in order to influence public policy reform process.

\section{Materials and methods}

\subsection{Sample Size and Sampling Procedure}

The research utilized a sample of n700 subjects constituting of Correctional Service employees in various grades randomly selected from a possible target $\mathrm{N}$ population of $=1000$ to understand the factors that affect employee performance. The study implored a probability one's stage cluster sampling design to select six departments/units from the total 13 for the study. The sample included the civilian staff, senior management, middle management and subordinate level staff mainly to balance views. From the population of 1000, the sample n700 was distributed as follows;

Table 1 The study Sample Lesotho correctional Services.

\begin{tabular}{|l|l|}
\hline Position & Distribution \\
\hline Basic Officer & $14(2 \%)$ \\
\hline Chief Officer & $14(2 \%)$ \\
\hline Correctional Officer & $672(96 \%)$ \\
\hline
\end{tabular}


The respondents were randomly selected, sample calculated observing the degree of confidence 90\% (alpha error of 0.1). To validate data and missing information, the study scheduled to interview 10 key informants, purposively targeting essential service offices from the Human resources, Commissioner level Operations, Finance and Administration, rehabilitation, security and protection.

\subsection{Data Collection Instruments}

Data was collected using a self-administered structured questionnaire randomly distributed amongst the subjects. The questionnaires were distributed randomly so as to minimize occurrence of undesired responses. The questionnaire had close ended questions for easy coding of responses. The data collection tool was first tested amongst 10 Correctional Service Officer grades for adjustments and language clarity, respectively all adjustments were effected prior to the commencement of the main research. The questionnaire collected data on demographic, validating on factors known as affecting employee performance and sought for a binary response on study assumptions. The study further used semi structured interview guide to gather elaborative or rather detailed information regarding factors that could affect staff performance and further to explore thoughts, feelings and beliefs about performance issues. Moreover, a desk review of Lesotho Correctional Service policies and more than 40 published articles on correctional services staff performance, attitudes and workplace behavior was carried out to develop the study theoretical framework and selection of study variables. Lastly, the researchers' observations and experiences in the Lesotho Correctional Service formed part of the data used in drawing conclusions.

\subsection{Data Analysis}

The data collected was collated to give descriptive summaries, cross tabulation was done on variables likely to influence staff performance. Responses from the questionnaires were converted into numerical codes for inferential statistical analysis. The study further conducted logistic regression analysis to determine the strength and character of the relationship between study dichotomous dependent variable; (employee performance) and independent variables (leadership style, employee participation, working environment, organizational culture and motivation). The study conducted inferential analysis which involved model validation through an evaluation of the coefficient of determination and multiple regression analysis. In analyzing data and modelling, the study finally used n400 respondents who had perceived as binary yes response that the study independent variables may affect employee performance at Lesotho Correctional Service. The research used Epi Info Statistical software to analyze data at significance level $<0.05$.

\section{Results and discussion}

The research utilized $n 400$ respondents who perceived yes employee performance is affected by proposed study independent variables, from a population of $\mathrm{N}=1000$ employees constituting the Lesotho Correctional Service for analysis and estimation. Out of the $n$ sample size, the research achieved a $73 \%$ response rate used to draw conclusions on staff performance in the Correctional Service.

Table 2 Socio-demographic characteristics of respondents, Lesotho Correctional Service 2019.

\begin{tabular}{|l|l|}
\hline Characteristic & Frequency (\%) \\
\hline Male & $240(60)$ \\
Female & $160(40)$ \\
\hline Age group in years: Less than 20 & $28(4)$ \\
$20-30$ & $175(25)$ \\
$31-45$ & $462(66)$ \\
46 years and above & $35(5)$ \\
\hline
\end{tabular}

Table 2 shows the majority (66\%) of the respondents were aged between 31 - 45 years, $46 \%$ had their highest educational level being certificate, $63 \%$ had worked for more than 7 years and of the majority of respondents, $96 \%$ were at Correctional Officer level. There was a considerable size, $23 \%$ has served less than $<1$ year in the service. On factors affecting Lesotho Correctional Service staff performance the mean and standard deviations were calculated on tested variables as in Table 3. 
Table 3 Factors affecting staff performance at Lesotho Correctional Service.

\begin{tabular}{|l|l|l|}
\hline Variable & Mean & Standard deviation \\
\hline Leadership styles & 3.51 & 1.33 \\
\hline Coaching & 4.67 & 2.55 \\
\hline Training & 3.89 & 1.99 \\
\hline Working environment & 4.88 & 2.39 \\
\hline Participation & 4.22 & 1.67 \\
\hline Empowerment & 3.57 & 2.52 \\
\hline Organizational justice & 4.77 & 1.56 \\
\hline Motivation & 3.65 & 2.36 \\
\hline
\end{tabular}

Table 3 showed work environment perceived with the greatest influence on Lesotho Correctional Service employee performance as evidenced by a mean of 4.88 . The other important factors affecting employee performance were organizational justice (mean=4.77), staff coaching (mean=4.67) and employee participation (mean=4.22). Leadership style (mean=3.51), employee empowerment (mean=3.67), employee motivation (mean=3.65) and employee training (mean $=3.89$ ) were other factors which influenced Lesotho Correctional Service employee performance.

Leadership styles used in the department such as openness at the workplace and employee participation were assessed on how they are related to employee performance. The majority of respondents (68\%) supported the view that openness at the workplace is related with Lesotho Correctional Service employee performance. About $12 \%$ were neutral suggesting they are neither sure whether their leadership is practicing openness hence likely not to effectively perform. Employee participation plays an important role in influencing performance as it helps employees appreciate organizational environment and instills sense of ownership. The distribution of responses showed $63 \%$ agreed that employee participation in service programmes at Lesotho Correctional Service is perceived influencing the way they perform. Leader- employee relationship plays an important role in employee performance. The study revealed $60 \%$ of the respondents agreed that leadership style gives motivation for employees to effectively perform. However, $22 \%$ of the respondents were neutral, $8 \%$ disagreed and 10\% strongly disagreed that leadership style is related to employee performance, suggestive amongst the respondents are those who had long service in the force, have found attachment to the Correctional Services despite negative effects from existing leadership. Of the respondents, $68 \%$ indicated their supervisors are very autocratic and never acknowledge when they perform well but immediately a mistake happens disciplinary measures are always considered. Thus indicated the rigidity of supervisors make it difficult for employees to perform well. A demotivated employee is likely not to effectively perform.

Appreciating good performance of employees is a great morale boost and it makes employees to put more effort on the subsequent duties. Majority (78\%) of the respondents supported the view that if an employee feels that employers are not appreciating them for their good performance then they will not perform as expected. A motivated workforce is critical in any organization. Theory proved employees can be motivated amongst others by good salaries and allowances, appreciation by supervisors and availability of development opportunities [35]. Results from the study showed $70 \%$ of the respondents supported the claim that at Lesotho Correctional Service, motivation has an impact on employee performance.

Having established the key factors relevant in influencing employee performance based on respondents' perceptions, the study developed an inferential statistic model in explaining employee performance as a depend variable. Five independent variables (leadership style, employee participation, working environment, organizational culture and motivation) were used to build the model to determine the association between the independent variables and employee performance. The study conducted inferential analysis which involved model validation through an evaluation of the coefficient of determination and multiple regression analysis. The model coefficient was as follows; 
Table 4 Model Summary

\begin{tabular}{|l|l|l|l|l|}
\hline Model & R & R Square & Adjusted R Square & Standard error of estimate \\
\hline 1 & 0.821 & 0.674 & 0.541 & 0.0338 \\
\hline
\end{tabular}

The coefficient of determination, $\mathrm{r} 2$ become the square of the sample correlation coefficient between outcomes and predicted values explaining the contribution of the six independent variables (leadership style, employee participation, employee empowerment, organizational culture and motivation) to the dependent variable (employee performance). The five independent variables studied explain $67.4 \%$ of the staff performance in the Lesotho Correctional Service as represented by the R2. This thus means other factors not studied in this research contribute $32.6 \%$ on employee performance.

The multiple regression analysis on the determinants of Lesotho Correctional Service employee performance using a forward and backward elimination method to come up with the best model presented as;

$$
(\mathrm{Y}=\beta 0+\beta 1 \mathrm{X} 1+\beta 2 \mathrm{X} 2+\beta 3 \mathrm{X} 3+\beta 4 \mathrm{X} 4+\beta 5 \mathrm{X} 5+\varepsilon)
$$

Table 5 Regression Coefficients.

\begin{tabular}{|l|l|l|l|}
\hline \multirow{2}{*}{ Model (Constant) } & \multicolumn{2}{|l|}{ Unstandardized Coefficients } & \multirow{2}{*}{ P Value } \\
\cline { 2 - 3 } & $\beta$ & Std. Error & 0.157 \\
\cline { 2 - 3 } & 2.192 & 1.212 & 0.026 \\
\hline Leadership style & 0.712 & 0.11 & 0.022 \\
\hline Organizational culture & 0.611 & 0.322 & 0.025 \\
\hline Employee participation & 0.325 & 0.143 & 0.029 \\
\hline Employee motivation & 0.814 & 0.451 & 0.003 \\
\hline Working environment & 0.312 & 0.221 & \\
\hline
\end{tabular}

The regression equation established that when taking all factors into perspective (leadership style, employee participation, working environment, organizational culture and motivation) constant at zero, employee performance at Lesotho Correctional Service will be 2.192. The presented findings further showed, considering all other independent variables at zero, leadership style will lead to a 0.712 improvement in employee performance. As was purported by John C. Maxwell, "everything rises and falls on Leadership", the quote by [36] has found its ground in the Lesotho Correctional Service suggesting leadership style is at the pinnacle of directing how employees perform. Therefore, leadership styles used within the force though widely perceived as autocratic because of being a paramilitary institution, need to cater for various levels to keep motivation high. The study model revealed a change from the current Lesotho Correctional Service organizational culture will lead to performance improvement by 0.611 thus confirming organizational culture has significant bearing to employee performance. Studies that have been conducted on the impact of leadership on staff performance have cemented the findings as they suggested that autocratic style of leadership negatively affects staff performance. Literature has suggested that autocratic leaders retain for themselves the decision- making rights [28]. Anyango suggests that autocratic leadership is detrimental to any organizational performance because of the tendency for such leaders to impose their often subjective ideas [28] hence there is little motivation amongst employees. However, what is of interest from the study as opposed to the literature is that senior management did not see leadership as having an impact on their performance. This could be attributed to the level of qualifications which are on average a first degree, and the level of experience together with the environment which is somewhat relaxed as opposed to the operational level.

An improvement in employee participation will lead to a 0.325 times improvement in employee performance while employee motivation will lead to 0.814 improvement in employee performance at Lesotho Correctional Service. The study results are similar to [37] study when measuring motivation within civil service, who established there exists a positive relationship between performance and motivation. As was established in the Adams Equity theory and other 
scholars, the study further confirms the theoretical assertions that when employees are demotivated in an organization, they are expected to withhold effort, restrict expected work output or lower product even quality [38]. Motivational issues in the department need to be equally supported and planned for as to transform productive performance. The relationship proved in the model supports assertions by [39.40] who observed whenever employees find high level enriching job characteristics, there are greater chances for the workforce to exhibit accelerated psychological engagement that eventually induce high levels of employee satisfaction and performance. Best practices from Chinese leadership ideology in the Prison service force maybe good lesson that maybe adapted into Lesotho Correctional Service. The Chinese leadership ideology emphasize on procedural fairness, clarity on standards, rules and procedures supremacy and morality given over enforcing punishment by leaders based on Confucianism's moral standards [41]. Procedural fairness plays an important role in the employee performance. Institutional standards and rules are meant to be adhered to consistently to maintain fair practices and improve on organizational justice. Majority of respondents (69\%) supported the view that adherence to set standards and rules enhance employee performance.

In mitigating against non-performance, $79 \%$ of the respondents believed performance management remains a strategy which can be used by Lesotho Correctional Service to enhance employee performance. However, few (12\%) of the respondents disagreed that performance management is a strategy that can be used at Lesotho Correctional Service to enhance employee performance. However, the senior officers were of the view that it is imperative that performance management system be tailor made for correctional setting unlike in the past when the government never took cognizance of the specifics of correctional settings. The key informants indicated however it will be imperative that prior implementation of appraisals, the department develops necessary policies so that the implementation becomes easy and accepted. Use of incentives and or performance based reward system is one strategy that enhances motivation and instills accountability on employees. Scholarly consensuses indicate lack of development opportunities affects morale as employees feel overwhelmed by responsibilities [42]. Targeted interviews with the Commissioner level respondent confirmed the department lacks in availing development opportunities for staff thus in turn affects the way they perform their duties. Only induction training is provided to employees on arrival and no other development opportunities availed thereafter. To stress on this point one respondent stated; "how do you expect me to perform maximally as a manager when I was never provided with training prior to my promotion to management"?

The human resources indicated it was really challenged in terms of providing trainings for Correctional Service employees because for the past five years (2015-2019) the department has not been allocated any budget towards staff training. Most of the department's budget is geared towards inmate's welfare hence staff performance has been always compromised.

Indeed, running a correctional facility in the twenty first century calls for expertise in information technology due to the sophistication in crime. It became impossible to run professional correction service with limited building of capacities in order to induce high performance. Other key informants highlighted the need for the Correctional Service to be adequately resourced including; adequate funding to secure items i.e. CCTV for monitoring inmates, issuance of replacements for uniforms, working on providing adequate office space as part of working environment for purposes of offering counseling to inmates quite often. Mboi in his study found out that availability of resources such as equipment plays a key role in determining how well employees will perform and argues that having equipment would impact performance to a great extent by 77.1\% [2]. Advice from management grades was the need to amend the Lesotho Correctional Service Act No.3 of 2016 that regulates the organization, administration and discipline of the members, to allow for other regulations that may have direct impact on employee performance to be crafted. Of the respondents, $46 \%$ suggested the need to frequently change department commissioners as it may impact on stability of the organization. One respondent indicated said;

"the frequent change of the Commissioners has affected our strategic direction because of the fact that the department does not have a strategic plan, each commissioner brings his/her own agenda which eventually distorts whatever plans we might have made".

Respondents indicated low salaries and allowances in the Correctional Service are low hence affected their performance. The observation is supported by [43] who opinionated an employee is more likely to perform to his potential if the salary is satisfactory. The author argues that earning a high salary is motivation for an employee to do their job well, because he wants his employer to be pleased which will lead to him retaining his position. The level of salary and allowance has a significant impact on motivation hence it can affect performance. One respondent said "our salaries are very low and the standard of living is increasing and this does not give someone the urge to come to work".

To such an employee, salary brings a feeling of security, allows him to feel accomplished and a person is much more willing to exert more effort because he feels his financial rewards are a fair trade-off. Fifty (50) \% of the respondents 
suggested the government needs to facilitate the salary restructuring for the Correctional Service if it wishes to enhance staff performance within the service. Generally career progression opportunities are limited for Correctional Service Officers suggestive of being one of the sources of de-motivators pointing to low performance.

In enhancing staff performance within Lesotho Correctional Service, there may be need to use performance reward based system together with use of incentives. However, it is imperative that use of incentives gets institutionalized as it has been suggested by literature that without proper regulations use of incentives could be a recipe for conflicts. Use of incentives need to be institutionalized to avoid any use based on personal judgments of managers. The department needs to ensure that use of incentives is clearly documented in the policies. In [44] ground breaking study; use of incentives enhances performance by anywhere from 25 to 44 percent, incentive programs engage participants and incentive programs attract quality employees. Equally performance management system needs to be re-casted to inspire performance. In establishing the effectiveness of performance management system, Comaford established performance reviews received inspired employees to improve and feedback receive helps them to do their work even better. It is also imperative that the department puts measures of incentivizing ethical conduct to enhance professional conduct amongst the officers. The department needs to provide leadership training for managers to enhance smooth work relations.

\section{Conclusion}

Correctional Service staff remain key for any national correctional agency thus issues affecting staff performance ought to be identified and attended to so as to reduce staff turnover which tend to be very costly for correctional organizations. Once employee satisfaction is achieved, there is strong effect that such correctional staff will be engaged hence help in attaining correctional services and rehabilitation program goals.

\section{Compliance with ethical standards}

\section{Acknowledgments}

The researchers would like to thank the valuable cooperation from the Lesotho Correctional Service Commissioner and Peking University who partially supported the researchers' expenses in conducting this study.

\section{Disclosure of conflict of interest}

The authors declare that they have no competing interests.

\section{Statement of ethical approval}

Authorization to conduct this study was sought from the Commissioner of Lesotho Correctional Service. The researchers made the participants aware of the objectives of the research and participated voluntarily. The researchers assured participants of confidentiality of the responses and also reaffirmed by the design of the questionnaire which did not require the participant to fill his/her name.

\section{References}

[1] Bohatala. Factors affecting employee performance. Human Resource Papers. 2019.

[2] Mboi MS. Factors influencing the performance of public servants in Kenya: A case of Machato County. unpublished thesis, University of Nairobi. 2014.

[3] Sefali FT, Bekker JC. The impact of the performance management system on accountability in the public service of Lesotho, African Journal of Public Affairs. 2012; 5(1).

[4] Lesotho Times. Lesotho Correctional Service Commissioner suspended. 2016.

[5] Kutloano Pheko. The birth and the existence of Lesotho: A diplomatic lesson. Unpublished Master Thesis, University of Matla, Ireland. 2017.

[6] Urwick J, Mapuru P, Nkhoboti M. Teacher motivation and incentives in Lesotho. 2005.

[7] Monyane T, Okumbe J. An evaluation of cost performance of public projects in the Free State Province of South Africa. Proceedings of the 2nd NMMU Construction Management conference. 2012; 25-27. 
[8] Tirintetaake I. Scientific management theory Vs Human relations theory. 2017.

[9] Ronald Busse, Warner M. The legacy of the hawthorne experiments: A critical analysis of the human relations school of thought, History of Economic Ideas. 2017; 25(2): 91-114.

[10] Vroom VH. Work and motivation. New York, Wiley \& Sons. 1964Heathfield, S. M. Performance management. Performance Management is NOT an Annual Appraisal. 2020.

[11] Ombima OR, Were S. Factors Affecting the Performance of Uniformed Officers of the Kenya Prisons Service. European Journal of Business Management. 2014; 2(1): 173-189.

[12] Arinanye RT. Organizational factors affecting employee performance at the college of Computing and Information Sciences (COCIS) Makerere University Kampala Uganda, Int Journal of Technology and Management. 2016; (1): $1-11$.

[13] Hwang LTT, Thao JC. Factors affecting employee performance: Evidence from Petrovietnam Engineering consultancy J.S.C. 2002.

[14] René Darmon Salesmen's Response to Financial Incentives: An Empirical Study, Journal of Marketing Research. (November 1974); 11: 418-26.

[15] Denton DK. What's wrong with these employees? Business Horizons. September-October 1991; 34 (5): 45.

[16] Carrell RM, Kuzmits FE, Elbert NF. Personnel: human resource management 4th edition. Merrill Publishing Company. 1992.

[17] Lambert Eric G, Hogan Nancy L, Barton, Shannon M. Satisfied Correctional Staff: A Review of the Literature on the Correlates of Correctional Staff Job Satisfaction Peer Reviewed Publications. 2002; 13.

[18] Kerce EW, Magnusson P, Rudolph A. Attitudes of navy corrections staff members: What they think about confinees and their jobs. San Deigo, Navy Personnel Research \& Development Center. 1994.

[19] Lambert EG, Hogan NL, Barton SM. The impact of work-family conflict on correctional staff job satisfaction: An exploratory study. American Journal Crime Justice. 2002; 27: 35.

[20] Mazin R. Factors that affect employee performance in an organization. 2017.

[21] Khaled A, Haneen O. The Influence of Work Environment on Job Performance: A Case Study of Engineering Company in Jordan, Int J of Applied Eng Research. 2017; 12(24).

[22] Herzberg et al. The Motivation to work New York, Wiley. 1999.

[23] Cherry K. Extrinsic vs intrinsic motivation: Differences of Extrinsic and Intrinsic Motivation. 2018.

[24] Soleas EK. Leader strategies for motivating innovation in individuals: a systematic review. Journal Innov Entrep. 2020; (9): 9.

[25] Dana Al Rahbi et al. The Effects of Leadership Styles on Team Motivation, Academy of Strategic Management Journal. 2017; 16(2).

[26] A Mohammad Mosadegh Rad, M Hossein Yarmohammadian. A study of relationship between managers' leadership style and employees' job satisfaction, Leadership in Health Services. 2006; 19(2): 11-28.

[27] Anyango, Celestine Awino. The effect of leadership styles on employees' performance at Bank of Africa, Kenya ltd. The Open University of Tanzania. 2015.

[28] Wigger E. Organizational Justice. The Center for Social Epidemiology. 2011.

[29] Kuchinke, P. and Asrar-ul-Haqa M. Impact of leadership styles on employees' attitude towards their leader and performance: Empirical evidence from Pakistani banks, Future Business Journal. 2016; 2: 54-64.

[30] Obasan H, Banjo K. A Test of the Impact of Leadership Styles on Employee Performance: A Study of Department of Petroleum Resources. 2014.

[31] Zhiren Z, Burns JP. Performance Management in the Government of the People's Republic of China: Accountability and Control in the Implementation of Public Policy. 2010.

[32] Burns JP. Performance Management in China -A Gradual Evolution. 2010.

[33] Bivins T. Ethics in Public Relations: Responsible Advocacy Responsibility and Accountability. Political Science. 2006. 
[34] Iqbal N, Anwar S, Haider N. Effect of Leadership Style on Employee Performance. Arabian Journal Bus Manag Review. 2015; 5: 146.

[35] John Maxwel. The 21 Irrefutable Laws on Leadership: Follow Them and People Will, Thomas Nelson Pub Inc, Harper Collins Leadership. 2007.

[36] Alonso P., \& Lewis, G. B. Public service motivation and job performance evidence from the federal sector. The American Review of Public Administration, 2001; 31(4), 363-380.

[37] Burgess S, M Ratto. The role of incentives in the public sector: Issues and evidence. Oxford Review of Economic Policy. 2003; 19(2): 285-300.

[38] Prendergast C. Intrinsic motivation and incentives. American Economic Review. 2008; 98(2): 201-205.

[39] Hackman JR. Work redesign and motivation. Professional Psychology. 1980; 11(3), 445-455.

[40] Wei Wu, Tom Vander Beken. Understanding Criminal Punishment and Prison in China, The Prison Journal. 2018; 98(6).

[41] Aidah Nassazi. Effects of training on Employee performance. Evidence from Uganda, Business Economics and Tourism, Vaasan Ammattikorkeakoulu University. 2013.

[42] Woods L. How salary influence a worker's performance in an administration? 2018.

[43] Stolovich H. Incentives, motivation and workplace performance: Research and practices. 2010.

[44] Comaford C. Why leaders need to embrace employee motivation. 2018. 